Research Article

\title{
Study of the Development of Carotid Artery Atherosclerosis upon Oxidative Stress using Infrared Spectroscopy and Scanning Electron Microscopy
}

Jane Anastassopoulou ${ }^{1,2}$, Ioannis Mamarelis ${ }^{3}$, Theophile Theophanides ${ }^{2, *}$

1. International Institute for Anticancer Research, 1st km Kapandritiou-Kalamou Road, Kapandriti, Attiki, 1901, Greece; E-Mail: i.anastassopoulou@gmail.com

2. National Technical University of Athens, Chemical Engineering School, Radiation Chemistry \& Biospectroscopy, Zografou Campus, 15780, Athens, Greece; E-Mail: theo.theophanides@gmail.com

3. 401 General Military Hospital, Cardiovascular Department, Athens, Greece; E-Mail: imamarelis@gmail.com

* Correspondence: Theophile Theophanides; E-Mail: theo.theophanides@gmail.com

Academic Editor: Douglas G. Walker

Special Issue: Research on Neurodegenerative Diseases

\section{OBM Geriatrics}

2021, volume 5 , issue 4

doi:10.21926/obm.geriatr.2104180
Received: March 07, 2021

Accepted: September 29, 2021

Published: October 12, 2021

\begin{abstract}
In the present study, Fourier-transform infrared (FTIR) spectroscopy and Scanning Electron Microscopy (SEM) were used to investigate the formation and development of carotid artery atherosclerosis. The FTIR spectra showed that with the progression of atheromatic plaque formation, the collagen changed its native structure from a-helix to random coil, amyloid, and cross-links. The infrared spectra and SEM analysis of carotid arteries showed that higher than $65 \%$ of the atheromatic plaque in patients with stenosis consisted of calcium carbonate, which lies inside foam cells. However, as the stenosis progresses, these deposits of calcium phosphate become more prevalent. A thorough analysis of the SEM images highlighted that mineral deposits preferred the carboxyl groups of amino acids. The intensity and shape
\end{abstract}

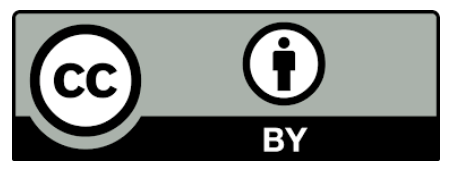

(C) 2021 by the author. This is an open access article distributed under the conditions of the Creative Commons by Attribution License, which permits unrestricted use, distribution, and reproduction in any medium or format, provided the original work is correctly cited. 
changes in FT-IR spectra in the region of $1200-900 \mathrm{~cm}^{-1}$ were related to elevated serum glucose and uric acid levels, the formation of advanced glycation end products (AGEs), and the involvement of free radicals during atherosclerosis.

\section{Keywords}

Atherosclerosis; oxidative stress; carotid arteries; infrared spectroscopy; scanning electron microscopy

\section{Introduction}

Geriatrics (Gerontology) is the field concerning the science and medical care of old aged people. Atherosclerosis, a degenerative disease, is the most common cause of death in the western world among the elderly. The pathogenesis of atherosclerosis involves not only the aging process but also other factors such as high cholesterol, diabetes, smoking, obesity, etc. [1-4]. Atherosclerosis is a diffuse, silently evolving disease, with its focal clinical manifestations being increased morbidity and mortality. Morbidity and mortality usually occur due to thrombotic complications due to eroded or ruptured atherosclerotic plaques [5]. Many direct and indirect observations suggest that oxidative stress is involved in the development of many degenerative diseases, such as Alzheimer's Disease $(A D)$, Parkinson's Disease (PD), cardiovascular disease(CD), Diabetes mellitus (DB), and cancer (CA), which progress in a more accelerated manner with age [6-12]. The term oxidative stress was introduced by $\mathrm{H}$ Sies in 1985 to characterize the imbalance of endogenous antioxidants and free radicals (reactive oxygen species, ROS) [11]. Oxidative stress is characterized and identified mostly from the presence of certain end-products and the involvement of oxygen molecule $\left(\mathrm{O}_{2}\right)$ and its superoxide anion $\left(\mathrm{O}_{2}^{-*}\right)$ in the final steps of several free radical reactions and the electron transfer reactions [9]. Many papers have shown that oxidative stress provokes inflammation, ischemia, and cardiovascular disease $[6-11,13,14]$. Free radicals are continuously produced endogenously in living cells from various metabolites and externally through exposure to cosmic rays, medical diagnostic techniques, and xenobiotics, all leading to free radical production. Free radicals, due to the presence of unpaired electrons, are highly reactive species and tend to give or attract electrons to pair and stabilize them. In all cases, it is necessary to have electron transfer reactions, which activate oxygen molecules as electron acceptors and accumulate damaged products, thereby inducing pathological effects. On the other hand, cells need strong antioxidant compounds as well either to act as inhibitors (scavengers) [12] or to recover damaged biological molecules. The best scientific information about the mechanism of free radical reactions comes from studying radiation chemistry. This is because by irradiating aqueous solutions or solid biological molecules, it is possible to produce excessive amounts of free radicals, generate electron donors or acceptor sites, change parameters, and identify intermediate products at the various steps of reactions.

Atherosclerosis is no longer considered to be a simple lipid accumulation disorder but rather a pathological process characterized by the dynamic interaction of endothelial dysfunction and repetitive cycles of smooth muscle cell healing. Epidemiological studies have shown an increased vascular risk in individuals with elevated levels of cytokines, such as interleukin-6 and tumor necrosis factor (TNF $\alpha$ ) of cellular molecules, such as the intercellular adhesion molecule -1 (ICAM-1), P- 
selectin, and acute-phase proteins, such as a C-reactive protein (CRP), fibrinogen and serum amyloid A $[2,15,16]$. In addition, the results of clinical trials show that the reduction in cardiovascular disease risk achieved with agents that also have anti-inflammatory properties, such as statins, is significantly greater in patients with objective evidence of inflammation [17].

Fourier-transform infrared (FT-IR) spectroscopy has gained considerable attention from the medical community as a valuable tool in the non-destructive (non-invasive) characterization and identification of the molecular features of complex systems, such as human tissues and body fluids. FT-IR is a very easy, sensitive, and cost-effective tool for the early diagnosis of diseases. FT-IR spectra are produced when infrared light falls on and interacts with human tissue or other sample types. It depends on the vibration of atoms in the molecules or biomolecules present in proteins, membranes, and DNA/RNA [18-20].

The FT-IR spectra provide a wealth of information not only about the changes that take place inside the molecular structures but also about the changes happening in the environment of biomolecules within the cell. The FT-IR spectra are very characteristic of the molecules and structures in the specimen, in addition to the "fingerprint region" that marks the characteristic changes induced to these biological molecules during disease progression [21-24]. Based on midinfrared spectra in the region spanning $4,000-400 \mathrm{~cm}^{-1}$ and results from the literature on normal and malignant tissues, it is clear that the FT-IR spectra can be used for clinical trials and in the diagnosis of cancer and other diseases $[25,26]$. Infrared spectroscopy has shown to be a very sensitive method for evaluating secondary protein structures in human tissues $[1,5]$ as well as other components, such as DNA, lipids, and phospholipids in a single spectrum [27-29]. An infrared spectroscopic analysis provides characteristic "marker bands" of the tissue from each patient and helps in differentiating between normal and damaged tissues, while also giving information about disease progression. The FT-IR spectra change in correspondence with the changes in tissue, thus giving new information simultaneously of all components of the tissue during the examination.

Although there is a growing body of scientific papers on the pathogenesis in clinical and animal models suggesting that the pathogenesis of carotid mineralization is a multifunctional process, they do not give any answers about the structural and conformational changes taking place at the molecular level. In particular, there is more to be learned about the degenerative diseases themselves.

In the present study, we used FT-IR spectroscopy [18-29] in combination with scanning electron microscopy (SEM) $[1,21,28]$ to study the mechanism of carotid artery mineralization and atheromatic plaque formation.

\section{Materials and Methods}

\subsection{Patients}

Fifty representative specimens of human carotid arteries from patients aged 53-85 years old, without a metabolic syndrome, who underwent carotid artery endarterectomy, were used. Histological evaluation showed that the atheromatic plaques did not have inflammation. The samples, immediately after removal, were fixed in formaldehyde buffer solution for four days. The samples were then washed using distilled water and dried under vacuum conditions. This method ensured that the infrared spectra were not influenced.

The Greek law of ethics for ex-vivo clinical research studies was followed while procuring the 
samples. The samples were taken after surgery of the patients according to Helsinki rules and the Greek ethics for ex-vivo clinical research studies.

\subsection{ATR-FT-IR Spectrometer}

The FT-IR spectra were recorded using a Nicolet 6700 Thermo scientific spectrometer, equipped with an Attenuated Total Reflection (ATR) accessory. With the ATR-FT-IR technique, the samples are not homogenized, allowing us to obtain the spectra in different sites of the tissue (mapping) for each patient. Each spectrum consisted of 120 co-added spectra at a spectral resolution of $4 \mathrm{~cm}^{-1}$, and the OMNIC 7.2a software was used for data analysis. Three carotid sections, each about $10 \mu \mathrm{m}$ thick, were obtained from each artery per patient to see the changes induced due to disease. Each infrared spectrum was compared with the corresponding infrared spectra of all other patients, taking into account clinical data, as well as the patients' risk factors.

\subsection{Scanning Electron Microscope (SEM)}

A scanning electron microscope from Fei Co, The Netherlands, was used for studying the aortic valve surface architecture. The SEM was combined with an Energy Dispersive X-Ray (EDX) apparatus for the analysis of the chemical elemental composition at different sites of the carotid arteries. It is noticed that there was no coating of the samples with carbon or gold.

\section{Results and Discussion}

\subsection{FT-IR Spectra}

In order to understand the carotid artery atherosclerosis development, we obtained FT-IR spectra from patients and compared these with the spectra for different sites of the same artery to study spectral changes. Figure 1 shows a comparison between representative FT-IR spectra taken from normal carotid artery tissue (a), a patient rich in lipid mineralized foam cells (b), and a patient with minerals deposited on the artery walls (c). From the comparison between these spectra, it becomes clear that the spectra show considerable differences in terms of band absorption, intensity, width, and shifts in all infrared spectral regions from 4,000-400 $\mathrm{cm}^{-1}$.

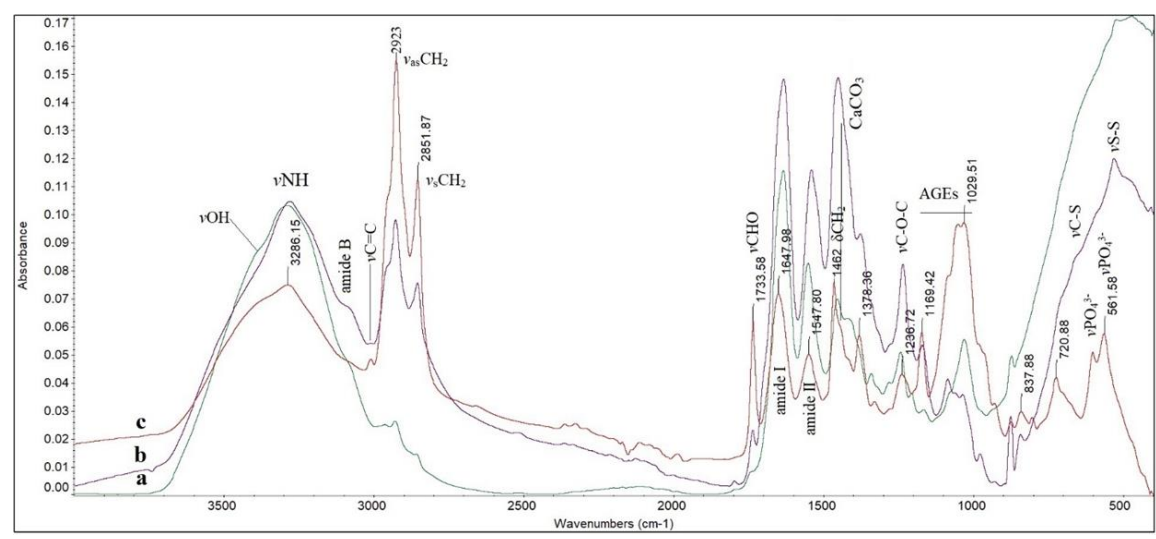

Figure 1 Representative FT-IR spectra of carotid biopsies: a; Normal carotid tissue b; Tissue with mineral deposits in the foam region, and c; Tissue with mineral deposits on the walls of the carotid artery. 
In the infrared spectral region of $4,000-3,000 \mathrm{~cm}^{-1}$, the characteristic stretching vibrational modes of $\mathrm{vOH}$ from water, alcohol, and saccharides of cells and tissues and $\mathrm{vNH}$ from proteins and DNA were detected. It was observed that these band shifts to lower frequencies in the spectra were approximately in the region from $3,000 \mathrm{~cm}^{-1}$ to $3,286 \mathrm{~cm}^{-1}$, while a broad shoulder was formed close to $3,100 \mathrm{~cm}^{-1}$. The shift of the absorption bands to lower frequencies suggests that the proteins changed their conformation of the secondary structure from amide $A$ to amide $B$ [21, 28-30]. This reflects the different strengths and lengths of the hydrogen bonds that hold protein strands together. A comparison of the spectra from foam cells (Figure 1c) with those from walls of the carotid artery (Figure $1 \mathrm{~b}$ ) showed that the intensity of stretching vibrations of the $v \mathrm{NH}$ bond decreased, suggesting greater damage of proteins. The band at about $3080 \mathrm{~cm}^{-1}$ was attributed to the stretching vibrations of $v \mathrm{CH}$ with olefinic character $[1,5]$. The intensity of this band is related to serum LDL and marks the involvement of free radicals $[1,21]$.

Important changes were observed in the region $3000-2850 \mathrm{~cm}^{-1}$, including the absorption bands representing the antisymmetric and symmetric stretching vibrations of methyl $\left(\mathrm{vCH}_{3}\right)$ groups and vibrations of methylene $\left(\mathrm{VCH}_{2}\right)$ groups in membranes, lipids, and phospholipids. In spectra $\mathrm{b}$ and $\mathrm{c}$ (see Figure 1), the intensities of absorption bands for $v_{a s} \mathrm{CH}_{2}$ and $v_{s} \mathrm{CH}_{2}$ in the spectra of the patients were quite prominent, while the intensities for the bands of $v_{a s} \mathrm{CH}_{3}$ and $v_{5} \mathrm{CH}_{3}$ decreased considerably. This suggested that the lipophilic environment had a higher conformational order and rigidity [1824]. The high-intensity band seen at $1,734 \mathrm{~cm}^{-1}$ was assigned to the aldehyde group $v \mathrm{CHO}$ resulting from lipid and protein peroxidation. The intensity of this band was more pronounced in patients with elevated serum LDL, oxidized collagen, and fibril formation. The aldehyde band was also observed for atheromatic plaques in calcified coronary arteries and aortic valves [10,28] and can be used as a "marker band" to characterize oxidized lipids and proteins arising from oxidative stress. This particular aldehyde band suggests that oxidative stress activates inflammation mechanisms leading to atherosclerosis.

Another prominent region in the spectra is the region between $1,700 \mathrm{~cm}^{-1}$ and $1,500 \mathrm{~cm}^{-1}$. In this infrared spectral region, appear the Amide I and Amide II absorption bands of proteins. Both are assigned to the bending $\delta$ - $\mathrm{NH}$ vibrations combined with the stretching of $v \mathrm{C}=\mathrm{O}$ carbonyl bands in the peptide (-NHCO-) [18-29]. The typical bands for vibrational absorption of Amide I and Amide II are found at about $1,655 \mathrm{~cm}^{-1}$ and $1,550 \mathrm{~cm}^{-1}$, respectively, for the native configuration, which is the $\alpha$-helix (Fig. 1a). The intensity of these bands is directly dependent on protein concentration and conformation. In almost all patients, these bands shift to lower frequencies, and some new bands appear in the same region. These changes were in accordance with the clinical data and risk factors of patients, such as high serum cholesterol, smoking, etc. Hence, the shifting of these bands to lower frequencies indicates the change in secondary structure from $\alpha$-helix to random coils and finally to $\beta$-sheet conformers $[21,28,29]$. These results also suggested changes in the strength of hydrogen bonds [30]. The high-intensity band at about $1,462 \mathrm{~cm}^{-1}$ is attributed to the bending vibration of methylene groups $\left(\delta \mathrm{CH}_{2}\right)$, and the shoulder near $1,445 \mathrm{~cm}^{-1}$ is assigned to the stretching vibration of calcium carbonate $\left(\mathrm{VCaCO}_{3}\right)$ [31]. The shape and intensities of bands depend on the amount of carbonate at the site of mineral deposits in the carotid artery. Moreover, the band at $1,445 \mathrm{~cm}^{-1}$ in the spectra was found to be broader in patients in whom the SEM-EDX study showed a high concentration of magnesium (Mg), as a result of the patient's nutrition according to the clinical data. Moreover, the excess $\mathrm{Ca}^{2+}$ ions released as carbonates are known to activate NADPH-oxidase leading to the development of oxidative stress [32]. 
The infrared spectral region 1,300-900 $\mathrm{cm}^{-1}$ is of high importance since in this region are located the characteristic absorption bands of - $\mathrm{C}-\mathrm{O}-\mathrm{C}$ groups of sugar moieties and C-O-P groups of phospholipids $\left(\mathrm{PO}_{2}^{-}\right)[18-20,33,34]$. This "fingerprint spectral region" gives information about the glycation and phosphorylation of proteins and phospholipids. The bands at $1,169 \mathrm{~cm}^{-1}$ and near $1,070 \mathrm{~cm}^{-1}$ are assigned to the $\mathrm{C}-\mathrm{OH}$ groups of sugars and sugar-phosphates, while the $\mathrm{C}-\mathrm{OH}$ of sugars at $1,029 \mathrm{~cm}^{-1}$ is attributed to the C-O-C stretching vibrations of glycogens [33, 34]. The intensity and shape of these bands are related to the progression of the disease, as well as to the risk factors. This region can be characterized as the "fingerprint region" of sugar molecules. In the spectra of patients with elevated carotid mineralization and stenosis, the intensity of these bands is higher (see Figure 1c). This is most likely due to the glycation of collagen under oxidative stress [34]. The glycation products (AGEs) were more prevalent in patients with elevated glucose in their serum, based on the clinical history of the patients. This is in concordance with literature data, where it is mentioned that the formation of AGEs is induced under the conditions of aging, hyperglycemia, dyslipidemia, and oxidative stress [35-37]. The ROS produced upon oxidative stress can react with lipids, proteins, sugars, and DNA to initiate a series of free radical reactions, as well as Millard-like reactions [35]. The dark yellow to brown color of carotid, which is observed in the region of foam cells, confirms protein glycation. The production of AGEs is also confirmed from the FT-IR spectral region of $3400-3500 \mathrm{~cm}^{-1}$ (Figure 1), where the appearance of the shoulder in the spectra for foam cells (see spectra c) derive from the stretching vibration of the hydrogen-bond $v O H$ groups of sugar fragments [38]. Deconvolution of the region (spectra not shown) gives bands at about $1237 \mathrm{~cm}^{-1}$ and $1080 \mathrm{~cm}^{-1}$ of $V \mathrm{PO}_{2}^{-1}$ for phospholipids and $900 \mathrm{~cm}^{-1}$ and $1100 \mathrm{~cm}^{-1}$ for $\mathrm{VPO}_{4}{ }^{3-}$ vibrations of calcium phosphate absorptions, which overlap with the bands of AGEs absorptions. The formation of calcium phosphate salts arises from the reaction between calcium cations and the negatively charged oxygen atoms of phospholipids and ATP in the membranes [10]. The involvement of oxidative stress in inflammation and atherosclerosis development is also confirmed from the absorption band near $522 \mathrm{~cm}^{-1}$, which originates from the vibration mode of $v S-S$ as a result of oxidized endogenous thiols [1,5]. Glutathione ( $\gamma$-glutamyl-cysteinyl-glycine) is the strongest antioxidant agent against free radicals that induce cell damage [39], and it interacts directly with highly reactive hydroxyl radicals, according to the following reactions [28]:

$$
\begin{gathered}
\mathrm{GRSH}^{+} \mathrm{HO}^{\circ} \rightarrow \mathrm{GRS}^{\cdot}+\mathrm{H}_{2} \mathrm{O} \\
2 \mathrm{GRS}^{\cdot} \rightarrow \mathrm{GRS}-\mathrm{SRG}
\end{gathered}
$$

The above reactions show the endogenous antioxidants undergoing reduction by scavenging the free radicals and inhibiting them from reacting with the other important biological molecules. Furthermore, it was observed that nicotinamide adenine-dinucleotide phosphate, NADPH, which is required to reduce the levels of oxidized glutathione decreases during metabolic diseases, aging, and oxidative stress [39-41], like the decrease in endogenous defense molecules, such as thiols and SOD promotes fibrosis [42].

\subsection{SEM-EDX Analysis}

Figure $2 \mathrm{~A}$ illustrates the architecture of the carotid artery of a patient who was a photographer. The architecture of the carotid is not homogenous, but it contains foam cells, fibrils, and dispersed 
mineral deposits in various sizes and morphologies. The arrow shows cross-links of damaged proteins and fibrils.

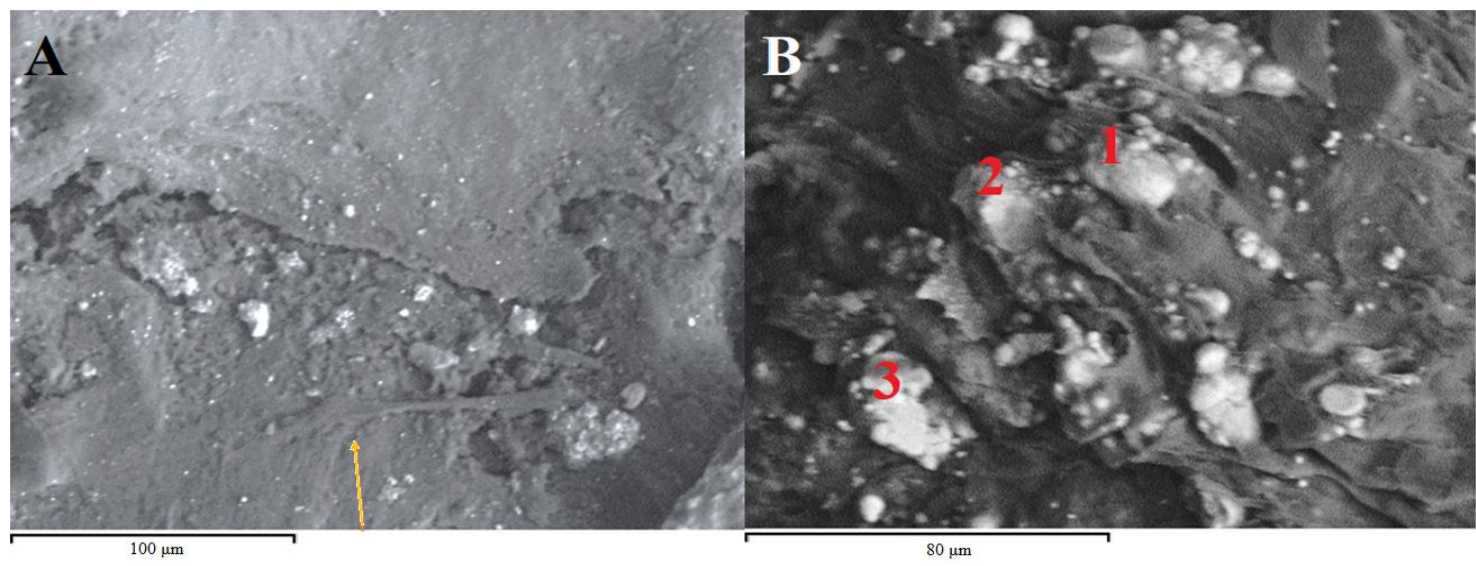

Figure 2 A: SEM-EDX illustration of carotid artery morphology. The arrow shows fibrils (Scale $100 \mu \mathrm{m}$, magnitude 100x). B: SEM-EDX at the foam cell region, rich in minerals (Scale $80 \mu \mathrm{m}$, magnitude 350x). The number 1 in red corresponds to calcium carbonate $\left(\mathrm{CaCO}_{3}\right)$ and calcium phosphate $\left[\mathrm{Ca}_{3}\left(\mathrm{PO}_{4}\right)_{2}\right]$ salts; the number 2 corresponds to a mixture of $\mathrm{MgCl}_{2} / \mathrm{MgO}$, and the number 3 represents silver atoms $(\mathrm{Ag})$.

At a higher magnification in (see Figure 2B) SEM-EDX, the chemical elementary analysis of minerals shows that point 1 is rich mostly in calcium carbonate and small amounts of calcium phosphates, while point 2 is a mixture of magnesium chloride $\left(\mathrm{MgCl}_{2}\right)$ and magnesium oxide $(\mathrm{MgO})$. Iseri and French [43] explained that $\mathrm{Mg}^{2+}$ ions inhibit the release of $\mathrm{Ca}^{2+}$ ions from the sarcoplasmic reticulum and block the influx of $\mathrm{Ca}^{2+}$ ions into the cell by inactivating the $\mathrm{Ca}^{2+}$ channels in the cell membrane to compete with $\mathrm{Ca}^{2+}$ ions in finding sites on troponin $\mathrm{C}$ and myosin and thereby inhibiting the ability of $\mathrm{Ca}^{2+}$ cations to stimulate myocardial tension. The most important finding was the detection at point 3 of the presence of silver atoms ( $\mathrm{Ag})$, which was related to the professional environment of the patient. In other sites of the same carotid artery were also detected $\mathrm{SiO}_{2}$ and $\mathrm{Al}_{2} \mathrm{O}_{3}$. These observations indicate that professional and environmental conditions induce oxidative ImageJ. Figure 3 illustrates the 3D ImageJ analysis of fibrils.

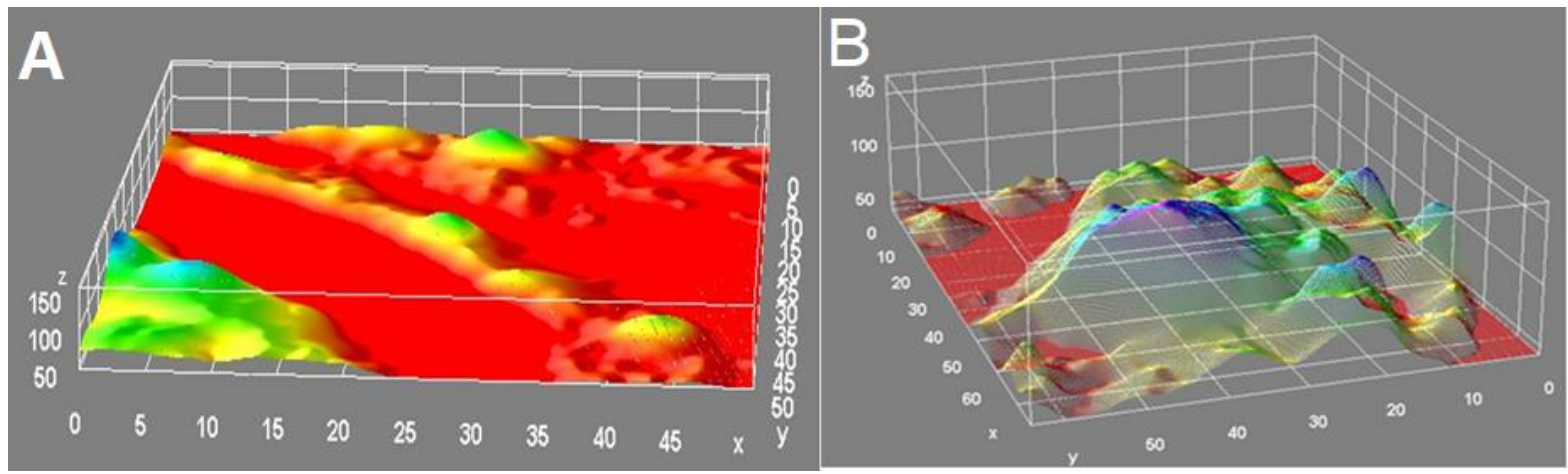

Figure 3 ImageJ is highlighted: A: Protein mineralization with a 3D image illustrating ImageJ way of mineral deposit formation and stenosis development in B as assigned at Figure 2. 
As is shown in Figure 3B, the green color, which indicates a high conductivity of the tissue results in a sequence following the mineralization. Further analysis of the green region (see Figure $3 \mathrm{~B}$ ) shows the presence of minerals indicating atherosclerosis progression.

SEM analysis also showed that in the carotid artery, the atheromatic plaques of hyperuricaemic patients were rich in molybdenum. From this finding, it is indicative that xanthine oxidase (XO), a molybdenum-iron sulfur flavoprotein, could not normalize the uric acid in patients. XO also acts as an electron donor to molecular oxygen, producing superoxide free radicals $\left(\mathrm{O}_{2}{ }^{-}\right)$leading to molybdenum (Mo atoms) release [23].

\section{Conclusions}

In this study, FT-IR spectroscopic data in combination with SEM-EDX analysis showed that calcium carbonates are the first mineral deposits in the region of foam cells inside atheromatic plaques and that the preferential parts are the amino acids, which contain carboxyl groups $(\mathrm{COOH})$ and can form carbonate groups with calcium. The vibrational frequencies of the infrared "marker bands" at about $3,080 \mathrm{~cm}^{-1}$ and $1,732 \mathrm{~cm}^{-1}$ are analogous to serum LDL of the patients resulting from the peroxidation of lipids, phospholipids, and proteins. This suggested an altered metabolic pathway of atherosclerosis and the influence of inflammation. The "fingerprint region" $1,200-900 \mathrm{~cm}^{-1}$ of the spectra was like a digital print, which characterizes protein glycoxidation with advanced glycation end products (AGEs). SEM-EDX analysis revealed that the proteins lose their secondary structure and that the mineral deposits prefer foam cells. Toxic metal ions such as Lead, Cadmium, Mercury, as well as transition metals from the environment, could trigger oxidative stress initiation. We conclude that FT-IR spectroscopy, in combination with SEM-EDEX analysis, can be used to characterize the atheromatic plaque's components by analyzing and interpreting the infrared spectra.

\section{Author Contributions}

loannis Mamarelis, MD,PhD, was responsible for the samples and the clinical interpretation. Professor Jane Anastassopoulou was responsible for FT-IR spectra and SEM analysis, as well as for the free radical chemistry. Professor Theophile Theophanides with Professor Jane Anastassopoulou were responsible for the editing, interpretation of the spectra and assignment of the bands.

\section{Competing Interests}

The authors have declared that no competing interests exist.

\section{References}

1. Mamarelis I, Pissaridi K, Dritsa V, Kotileas P, Tsiligiris V, Tzilalis V, et al. Oxidative stress and atherogenesis. An FT-IR spectroscopic study. In Vivo. 2010; 24: 883-888.

2. Rizza S, Copetti M, Cardellini M, Menghini R, Pecchioli C, Luzi A, et al. A score including ADAM17 substrates correlates to recurring cardiovascular event in subjects with atherosclerosis. Atherosclerosis. 2015; 239: 459-464.

3. Rizza S, Rossini V, Cardellini M, Luzi A, Longo S, Piciucchi G, et al. Diabetes influences cancer risk in patients with increased carotid atherosclerosis burden. Nutr Metab Cardiovasc Dis. 2020; 30: 
625-655.

4. Rizza S, Cardellini M, Farcomeni A, Morabitol P, Romanello D, Di Cola G, et al. Low molecular weight adiponectin increases the mortality risk in very old patients. Aging Dis. 2018; 9: 946-951.

5. Mamareli V, Tanis O, Kyriakidou M, Mamarelis I, Anastassopoulou J, Koutoulakis E, et al. Oxidative damage of carotid arteries in diabetic patients. Biomed J Sci Tech Res. 2018; 3: 32673272.

6. HuangW-J, Zhang X, Chen W-W. Role of oxidative stress in Alzheimer's disease. Biomed Rep. 2016; 4: 519-522.

7. Hwang O. Role of oxidative stress in Parkinson's disease. Exp Neurobiol. 2013; 22: 11-17.

8. Gautam N, Das S, Mahapatra SK, Chakraborty SP, Kundu PK, Roy S. Age associated oxidative damage in lymphocytes. Oxid Med Cell Longev. 2010; 3: 275-282.

9. Surh Y-J, Packer L. Oxidative stress and disease. New York: Taylor \& Francis; 2005.

10. Anastassopoulou J, Kyriakidou M, Kyriazis S, Mavrogenis AF, Mamareli V, Mamarelis I, et al. Oxidative stress in ageing and disease development studied by FT-IR spectroscopy. Mech Ageing Dev. 2018; 172: 107-114.

11. Sies H. Oxidative stress. London: Academic Press; 1985.

12. Pisoschi AM, Pop A, Iordache F, Stanca L, Predoi G, Serban Al. Oxidative stress mitigation by antioxidants-an overview on their chemistry and influences on health status. Eur J Med Chem. 2021; 209: 112891.

13. Parry TL, Melehani JH, Ranek MJ, Willis MS. Functional amyloid signaling via the inflammasome, necrosome, and signalosome: New therapeutic targets in heart failure. Front Cardiovasc Med. 2015; 2: 25.

14. Perry G, Cash AD, Smith MA. Alzheimer disease and oxidative stress. J Biomed Biotechnol. 2002; 2: $120-123$.

15. Neri M, Fineschi V, Di Paolo M, Pomara C, Riezzo I, Turillazzi E, et al. Cardiac oxidative stress and inflammatory cytokines response after myocardial infarction. Curr Vasc Pharmacol. 2015; 13: 26-36.

16. Shinde AV, Frangogiannis NG. Fibroblasts in myocardial infarction: A role in inflammation and repair. J Mol Cell Cardiol. 2014; 70: 74-82.

17. Devaraj S, Rogers J, Jialal I. Statins and biomarkers of inflammation. Curr Atheroscler Rep. 2007; 9: 33-41.

18. Theophanides T. Infrared spectroscopy materials science, engineering and technology. London: Intech Open; 2012.

19. Theophanides T. Infrared spectroscopy-life and biomedical science. London: Intech Open; 2012.

20. Theophanides T. Infrared spectroscopy-anharmonicity of biomolecules, crosslinking of biopolymers, food quality and medical applications. London: Intech Open; 2015.

21. Kotoulas E, Mamarelis I, Koutoulakis E, Kyriakidou M, Mamareli V, Tanis O, et al. The influence of diabetes on atherosclerosis and amyloid fibril formation of coronary arteries. A FT-IR spectroscopic study. Hellenic J Atheroscler. 2017; 8: 16-29.

22. Anastassopoulou J, Kyriakidou M, Malesiou E, Rallis M, Theophanides T. Infrared and Raman spectroscopic studies of skin molecular disorders and cancer. In Vivo. 2019; 33: 567-572.

23. Mamareli V, Tanis O, Anastassopoulou J, Kyriakidou M, Mamareli $\mathrm{CH}$, Koui M, et al. The role of oxidative stress on molybdenum enzymes and ischemic reperfusion injury in hyperuricaemic patients. An infrared spectroscopic study. EurJ Mol Clin Med. 2019; 6: 20-25. 
24. Anastassopoulou J, Kyriakidou M, Nisianakis P, Papatheodorou G, Rallis M, Theophanides T. The environmental effects of lead concentrations on protein and dna structures in epileptic patients from an infrared spectroscopic study. J Basic Appl Sci. 2019; 15: 56-63.

25. Eikje NS, Aizawa K, Ozaki Y. Vibrational spectroscopy for molecular characterisation and diagnosis of benign, premalignant and malignant skin tumours. Biotechnol Annu Rev. 2005; 11: 191-225.

26. Brancaleon L, Bamberg MP, Sakamaki T, Kollias N. Attenuated total reflection-fourier transform infrared spectroscopy as a possible method to investigate biophysical parameters of stratum corneum in vivo. J Invest Dermatol. 2001; 116: 380-386.

27. Anastassopoulou J, Kyriakidou M, Mamareli V, Tanis O, Rallis M. The influence of UV irradiation on diabetic mice skin. A vibrational FT-IR and Raman spectroscopic study. Chromatogr Spectrosc Tech. 2019; 2: 21-27.

28. Mamarelis I, Koutoulakis E, Kotoulas C, Dritsa V, Mamareli V, Anastassopoulou J. FT-IR spectroscopic study of amyloid protein formation and aortic valve calcification. Hellenic $J$ Cardiol. 2017; 58: 148-150.

29. Mavrogenis AF, Kyriakidou M, Kyriazis S, Anastassopoulou J. Fourier transform infrared spectroscopic studies of radiation-induced molecular changes in bone and cartilage. Expert Rev Qual Life Cancer Care. 2016; 1: 459-469.

30. Barth A. Infrared spectroscopy of proteins. Biochim Biophys Acta Bioenerg. 2007; 1767: 10731101.

31. Petra M, Anastassopoulou J, Theologis T, Theophanides T. Synchrotron micro-FT-IR spectroscopic evaluation of normal paediatric human bone. J Mol Struct. 2005; 733: 101-110.

32. Galán M, Kassan M, Kadowitz PJ, Trebak M, Belmadani S, Matrougui K. Mechanism of endoplasmic reticulum stress-induced vascular endothelial dysfunction. Biochim Biophys Acta Mol Cell Res. 2014; 1843: 1063-1075.

33. Conti C, Ferraris P, Giorgini E, Rubini C, Sabbatini S, Tosi G, et al. FT-IR Microimaging Spectroscopy: Discrimination between healthy and neoplastic human colon tissues. J Mol Struct. 2008; 881: 46-51.

34. Anastassopoulou J, Boukaki E, Conti C, Ferraris P, Giorgini E, Rubini C, et al. Microimaging FT-IR spectroscopy on pathological breast tissues. Vib Spectrosc. 2009; 51: 270-275.

35. Verzijl N, DeGroot J, Oldehinkel E, Bank RA, Thorpe SR, Baynes JW, et al. Age-related accumulation of Maillard reaction products in human articular cartilage collagen. Biochem $\mathrm{J}$. 2000; 350: 381-387.

36. Yamagishi SI, Nakamura K, Matsui T, Ueda S, Noda Y, Imaizumi T. Inhibitors of advanced glycation end products (AGEs): Potential utility for the treatment of cardiovascular disease. Cardiovasc Drugs Rev. 2008; 26: 50-58.

37. Chaudhuri J, Bains Y, Guha S, Kahn A, Hall D, Bose N, et al. The role of advanced glycation end products in aging and metabolic diseases: Bridging association and causality. Cell Metab. 2018; 28: 337-352.

38. Kyriakidou M, Mavrogenis AF, Kyriazis S, Markouizou A, Theophanides T, Anastassopoulou J. An FT-IR spectral analysis of the effects of $y$-radiation on normal and cancerous cartilage. In Vivo. 2016; 30: 599-604.

39. Mohanty J, Nagababu E, Rifkind JM. Red blood cell oxidative stress impairs oxygen delivery and induces red blood cell aging. Front Physiol. 2014; 5: 84. 
40. Kilanczyk E, Saraswat Ohri S, Whittemore SR, Hetman M. Antioxidant protection of NADPHdepleted oligodendrocyte precursor cells is dependent on supply of reduced glutathione. ASN Neuro. 2016; 8: 1759091416660404.

41. Shen J, Rastogi R, Geng X, Ding Y. Nicotinamide adenine dinucleotide phosphate oxidase activation and neuronal death after ischemic stroke. Neural Regen Res. 2019; 14: 948-953.

42. Martínez-Martínez E, Souza-Neto FV, Jiménez-González S, Cachofeiro V. Oxidative stress and vascular damage in the context of obesity: The hidden guest. Antioxidants. 2021; 10: 406.

43. Iseri LT, French JH. Magnesium: Natures physiologic calcium blocker. Am Heart J. 1984; 108 : 188-193.

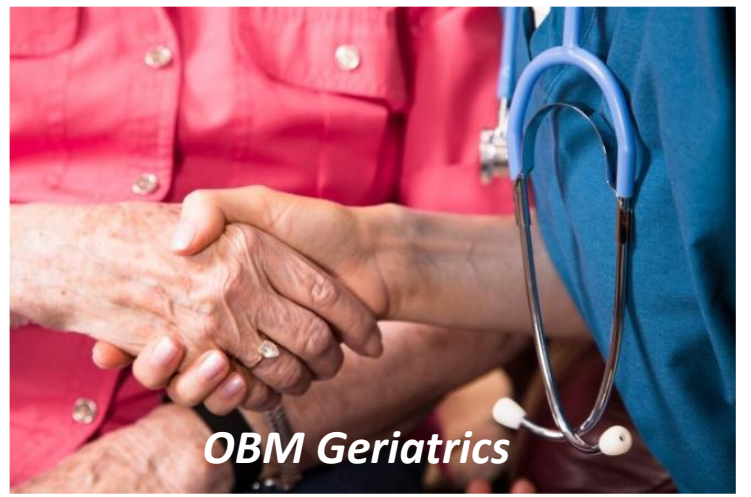

Enjoy $O B M$ Geriatrics by:

1. Submitting a manuscript

2. Joining in volunteer reviewer bank

3. Joining Editorial Board

4. Guest editing a special issue

For more details, please visit:

http://www.lidsen.com/journals/geriatrics 